medRxiv preprint doi: https://doi.org/10.1101/2021.11.15.21266368; this version posted November 16, 2021. The copyright holder for this preprint (which was not certified by peer review) is the author/funder, who has granted medRxiv a license to display the preprint in perpetuity.

\title{
Investigating the source of increased bipolar and major depressive disorder polygenic risk in multiplex schizophrenia families
}

Mohammad Ahangari ${ }^{1,2}$, Robert Kirkpatrick ${ }^{1,3}$, Tan-Hoang Nguyen ${ }^{1,3}$, Nathan Gillespie ${ }^{1,3}$, Irish Schizophrenia Genomics Consortium, Kenneth S. Kendler ${ }^{1,3,4}$, Silviu-Alin Bacanu ${ }^{1,3}$, Bradley T. Webb ${ }^{5}$, Brian C. Verrelli ${ }^{6}$, Brien P. Riley ${ }^{1,3,4}$

${ }^{1}$ Virginia Institute for Psychiatric and Behavioral Genetics, Virginia Commonwealth University, Richmond, VA, USA. ${ }^{2}$ Integrative Life Sciences PhD Program, Virginia Commonwealth University, Richmond, VA, USA. ${ }^{3}$ Department of Psychiatry, Virginia Commonwealth University, Richmond, VA, USA. ${ }^{4}$ Department of Human and Molecular Genetics, Virginia Commonwealth University, Richmond, VA, USA. ${ }^{5}$ GenOmics, Bioinformatics, and Translational Research Center, Biostatistics and Epidemiology Division, RTI International, Research Triangle Park, NC, USA. ${ }^{6}$ Center for Biological Data Science, Virginia Commonwealth University, Richmond, Virginia, USA.

Corresponding Author: Mohammad Ahangari, M.Sc., PhD Candidate, Integrative Life Sciences Program, Virginia Institute for Psychiatric and Behavioral Genetics, Virginia Biotechnology

Park, 800 E. Leigh St. Room 1- 110, Richmond VA 23219, USA. ahangarim@ @cu.edu 
medRxiv preprint doi: https://doi.org/10.1101/2021.11.15.21266368; this version posted November 16, 2021. The copyright holder for this

\section{Abstract:}

Psychotic and affective disorders often aggregate in the relatives of probands with schizophrenia (SCZ), and genetic studies show substantial genetic correlation among SCZ, bipolar disorder (BIP) and major depressive disorder (MDD). However, the nature of this genetic overlap in polygenic risk score (PRS) analyses of multiplex families has not been fully dissected. In the current study, we investigated the polygenic risk burden of BIP and MDD in a sample of 257 multiplex SCZ families $(\mathrm{N}=1,005)$ and population controls $(\mathrm{N}=2,205)$. Furthermore, due to the strong genetic correlation among SCZ, BIP, and MDD, we examined whether increased BIP or MDD PRS in members of multiplex SCZ families can be attributed to latent genetic factors unique to BIP or MDD, or latent genetic factors that each of these two disorders share with SCZ. Our results indicate that members of multiplex SCZ families have an increased PRS for BIP and MDD, however, this observation is largely attributable to latent genetic factors that BIP or MDD share with SCZ, rather than latent genetic factors unique to them. These results provide new insight for cross-disorder PRS analyses of psychiatric disorders, by cautioning that for complete interpretation of observed cross-disorder PRS enrichment, we should account for genetic correlations across psychiatric disorders. Our findings further indicates that members of multiplex SCZ families may have an increased genetic vulnerability to both psychotic and affective disorders, and for full assessment of an individual's genetic risk, familial backgrounds should be taken into consideration. 
medRxiv preprint doi: https://doi.org/10.1101/2021.11.15.21266368; this version posted November 16, 2021. The copyright holder for this

\section{Introduction:}

Psychotic and affective disorders have long been viewed as two separate axes of mental illness, but early practitioners of psychiatry like Emil Kraepelin and Eugen Bleuler observed that relatives of patients with schizophrenia (SCZ) have an increased rate of psychotic and affective disorders, many of which appeared to be milder versions of the symptoms observed in patients with SCZ (1). Some of the first family studies of SCZ conducted in the early $20^{\text {th }}$ century, confirmed that in addition to SCZ, a range of other psychiatric disorders also aggregate in the relatives of probands with SCZ (2). These findings were later solidified by the Danish Adoption Study of Schizophrenia, which showed that biological relatives of patients with SCZ were at an increased risk for SCZ and a spectrum of other psychiatric disorders $(3,4)$.

The Irish Study of High-Density Schizophrenia Families (ISHDSF) (5,6) consists of 257 multiplex SCZ families with genotype data, ascertained to have two or more first-degree relatives meeting the Diagnostic and Statistical Manual of Mental Disorders (DSM-III-R) criteria for SCZ or poor-outcome schizoaffective disorder (Supplementary Table 1). In line with previous epidemiological observations in the relatives of probands with SCZ $(5,7,8)$, a broad spectrum of other psychiatric diagnoses, including psychotic, affective, personality, and substance use disorders, are also present in the ISHDSF sample (6,9-12), with previous polygenic risk score profiling in the ISHDSF sample showing that all family members, including the unaffected individuals, have an increased burden of SCZ common genetic risk variation compared to population controls (13).

Results from the Psychiatric Genomics Consortium (PGC) Cross-Disorder Group (14,15), and other cross-disorder analyses of psychiatric disorders $(16,17)$ (Supplementary Figure 4), have provided robust, replicable evidence for strong genetic correlation $\left(\mathrm{r}_{\mathrm{G}}\right)$ between $\mathrm{SCZ}$ and bipolar disorder (BIP), and to a lesser degree between SCZ and major depressive disorder (MDD). The genetic correlation between SCZ and BIP is estimated to be $r_{G}=0.68$, and of the 64 genome-wide significant loci associated with BIP, 10 have previously reached genome-wide significance level in SCZ (18). SCZ and MDD also 
medRxiv preprint doi: https://doi.org/10.1101/2021.11.15.21266368; this version posted November 16, 2021. The copyright holder for this

have a significant positive genetic correlation estimated to be $\mathrm{r}_{\mathrm{G}}=0.35$, and in addition to substantial overlap among genes identified to be involved in the genetic architecture of MDD and SCZ, 6 of the 44 loci associated with MDD, are also associated with SCZ (19). BIP and MDD also have significant positive genetic correlation estimated to be $\mathrm{r}_{\mathrm{G}}=0.44(18)$.

The high baseline risk of SCZ observed across all diagnostic categories of ISHDSF sample, coupled with the evidence for cross-trait genetic correlations among SCZ, BIP, and MDD, and the presence of a wide spectrum of psychiatric disorders that aggregate in ISHDSF sample, raises two important questions. First, do members of multiplex SCZ families have an increased genetic risk for BIP and MDD? We constructed univariate BIP and MDD polygenic risk scores (PRS) to address the first question. Second, is the increased BIP or MDD genetic risk in multiplex SCZ families attributable to underlying latent genetic factors that BIP or MDD share with SCZ, or are they attributable to underlying latent genetic factors that are unique to BIP or MDD (hence, not shared with SCZ)? We used genomic structural equation modelling (genomicSEM) (20) and GWAS-by-subtraction (21) to perform a GWAS of latent, unmeasured factors underlying BIP or MDD to answer the second question. GWAS-by-subtraction is a newly developed method that facilitates the study and interpretation of residual values from genomicSEM models and provides insight into previously unmeasured latent genetic factors that are unique to individual phenotypes (21).

In addressing these two questions, we attempt to investigate the common risk variation burden of BIP and MDD, two co-morbid psychiatric disorders with SCZ, in families with multiply affected individuals with SCZ and related psychiatric disorders. Furthermore, we shed light on the complexity of cross-disorder PRS analyses of psychiatric disorders in multiplex families, by taking into consideration the underlying genetic correlation among SCZ, BIP, and MDD.

\section{Materials and Methods:}

\section{Sample Description}

Irish Study of High-Density Schizophrenia Families (ISHDSF) 
medRxiv preprint doi: https://doi.org/10.1101/2021.11.15.21266368; this version posted November 16, 2021. The copyright holder for this

Fieldwork for the ISHDSF sample was carried out between 1987 and 1992, with probands ascertained from public psychiatric hospitals in the Republic of Ireland and Northern Ireland with approval from local ethics committees (6). Selection criteria were two or more first-degree relatives meeting DSM-III-R criteria for SCZ or poor-outcome schizoaffective disorder (PO-SAD), with all four grandparents being born in either Ireland or the United Kingdom. Relatives of the probands suspected of psychotic illness were interviewed by trained psychiatrists, and trained social workers interviewed other relatives of the probands. To avoid bias and detect possible mistakes in diagnosis, independent review of all diagnostic information was made blind to family assignments by two trained psychiatrists, with each psychiatrist making up to 3 best estimate DSM-III-R diagnoses, with high agreement (weighted $\mathrm{k}=0.94$ $+-0.05)$.

The concentric diagnostic schema of the ISHDSF (Supplementary Figure 21), ranked by the degree to which they reflect the core vs periphery of the psychosis spectrum, includes 4 case definitions in the families as follows: narrow (SCZ, PO-SAD and simple SCZ), intermediate (adding schizotypal personality, schizophreniform, and delusional disorders, psychosis not otherwise specified (NOS), and good-outcome schizoaffective disorder, diagnoses that robustly and replicably aggregate in the relatives of SCZ probands), broad (adding psychotic affective illness, paranoid, avoidant and schizoid personality disorders and other disorders that significantly aggregated in relatives of SCZ probands in the Roscommon Family(10)), and very broad (adding any other psychiatric illnesses in the families). The ISHDSF sample also includes unaffected family members with no diagnosis of any psychiatric illness. Details of the ISHDSF sample are described elsewhere $(6,22)$.

\section{$\underline{\text { Population controls and replication singleton cases from Irish Schizophrenia Genomics Consortium }}$}

The Irish Schizophrenia Genomic Consortium (ISGC) sample was assembled for a GWAS of

SCZ in Ireland. Details of recruitment, screening, and quality control (QC) are described elsewhere (23).

Briefly, controls from the Irish Biobank used in ISGC were blood donors from the Irish Blood

Transfusion Service recruited in the Republic of Ireland. Individuals reported all four grandparents born 
medRxiv preprint doi: https://doi.org/10.1101/2021.11.15.21266368; this version posted November 16, 2021. The copyright holder for this

in either Ireland or the United Kingdom, with no reported history of psychotic illness. Due to the relatively low lifetime prevalence of SCZ in the general population $(\sim 1 \%)$, misclassification of controls should have a minimum impact on power (24). Singleton SCZ cases used as a replication in this study were recruited through community mental health service and inpatient units in the republic of Ireland or Northern Ireland following protocols with local ethics approval. All participants were interviewed using a structured clinical interview for DSM-III-R or DSM-IV, were over 18 years of age and reported all four grandparents born in Ireland or the United Kingdom. Cases were also screened to exclude substanceinduced psychotic disorder or psychosis due to a general medical condition. Detailed description for sample recruitment is provided in detail elsewhere $(13,25)$.

\section{Genotyping and QC}

Genotyping was carried out on 3 different arrays. 830 individuals from ISHDSF sample were genotyped on the Illumina 610-Quad Array. An additional 175 ISHDSF individuals, which either were not included in the Illumina Array study or did not pass QC, were later genotyped on the Infinium psychArray V.1.13 Array (the psychArray). For the ISGC sample, 1,730 population controls and 1,627 singleton cases were genotyped using the Affymetrix V.6.0 Array. An additional 475 population controls and 487 singleton cases that either did not pass the QC or were not included in the Affymetrix Array study were later genotyped on the psychArray along with the additional ISHDSF individuals. The same QC protocols were applied to all three datasets. In brief, exclusion criteria for samples were a call rate of $<95 \%$, more than one Mendelian error in the ISHDSF sample, and difference between reported and genotypic sex. Exclusion criteria for SNPs were MAF $<1 \%$, call rate $<98 \%$, and $\mathrm{p}<0.0001$ for deviation from Hardy-Weinberg expectation. The final ISHDSF sample includes 1,005 individuals from 257 pedigrees whose SNP data from the Illumina Array and the psychArray passed all the QC filters. The final ISGC sample includes 2,205 controls and 2,114 singleton cases whose SNP data from the Affymetrix and the psychArray passed all the QC filters (Supplementary Table 2). 
medRxiv preprint doi: https://doi.org/10.1101/2021.11.15.21266368; this version posted November 16, 2021. The copyright holder for this

\section{Imputation:}

Genotypes passing QC were phased using Eagle V.2.4 (26) and imputed to the Haplotype Reference Consortium (HRC) reference panel (27) on the Michigan Imputation Server using Minimac4 (28). The HRC panel includes 64,975 samples from 20 different studies that are predominantly of European ancestry, making the HRC suitable for imputation of our homogenous sample from Ireland. Each of the three genotype sets described in the previous step was imputed separately, and the imputed genotype probabilities were downloaded in VCF format from the Michigan Imputation Server. Genotype dosages were extracted and used for all downstream analyses. As part of the post-imputation QC, variants with MAF $<1 \%$ and $\mathrm{r}^{2}$ score of $<0.3(29)$ were excluded. After imputation and all QC measurements, 9,298,012 SNPs on the Illumina Array, 11,080,279 SNPs on the Affymetrix Array, and 11,081,999 SNPs on the psychArray, remained for analysis. Of these three sets of SNPs, 9,008,825 SNPs were shared across all three imputed arrays and were used for downstream analyses. Description of QC steps for the imputation are described in the Supplementary Materials and Supplementary Figures 1-3.

\section{Summary statistics acquisition}

We made use of the publicly available summary statistics data. PGC3-SCZ (67,390 cases and 94,015 controls) (30) and PGC3-BIP (41,917 cases and 371,549 controls) (18) summary statistics were downloaded from the PGC website. We used the 2019 MDD GWAS summary statistics from a metaanalysis of the PGC2-MDD and UK Biobank (excluding 23andMe), containing 170,756 cases and 329,443 controls (31). Low-density lipoprotein (LDL) summary statistics (N=87,048) (32) used as a negative control in this study was obtained from the ENGAGE Consortium website.

\section{GWAS-by-subtraction}

We investigated whether increased BIP and MDD PRS in multiplex families can be attributed to underlying latent genetic factors that are unique to BIP or MDD (not shared with SCZ), or underlying 
medRxiv preprint doi: https://doi.org/10.1101/2021.11.15.21266368; this version posted November 16, 2021. The copyright holder for this

latent genetic factors that BIP or MDD share with SCZ. We performed GWAS-by-subtraction within the genomicSEM framework by analyzing summary statistics data for SCZ $(\mathrm{N}=161,405)$, BIP $(\mathrm{N}=413,466)$, and MDD (N=500,199), by regressing SCZ and BIP or SCZ and MDD summary statistics on two latent variables that we called $S C Z$ factor and nonSCZ factor. Subsequently, we regressed $S C Z$ factor and nonSCZ factor on each SNP from the summary statistics, which allowed for two paths of association with BIP or MDD for each SNP: 1) a first path that is fully mediated by $S C Z$ factor, and 2) a second path that is fully independent of $S C Z$ factor, called nonSCZ factor (Supplementary Figure 5). Detailed description of GWAS-by-subtraction framework is provided in the original publication by Demange et al (21) and description of the current analysis, path estimates as well as the formula used to estimate the effective sample size for GWAS-by-subtraction analyses are provided in the Supplementary Materials and Supplementary Table 4.

\section{Estimation of SNP based heritability}

We used LDSC (33) to estimate the SNP-based heritability of the genomicSEM GWAS results and partition the heritability into functional categories and cell types. Since genomicSEM results rely on latent factors, it is not possible to estimate the heritability on liability scale, therefore, all the SNP-based heritability estimates are reported on the observed scale.

\section{Construction of Polygenic Risk Score}

Summary statistics for BIP (N=413,466), MDD (N=500,199, SCZ factor underlying BIP $\left(\mathrm{N}_{\text {eff }}\right.$ =149,460), nonSCZ factor underlying BIP ( $\left.\mathrm{N}_{\text {eff }}=312,118\right), S C Z$ factor underlying MDD $\left(\mathrm{N}_{\text {eff }}=149,464\right)$, and nonSCZ factor underlying MDD $\left(\mathrm{N}_{\text {eff }}=461,356\right)$ were first QC'd by excluding variants with MAF < $1 \%$ or imputation quality score of $<0.9$, and removing strand ambiguous and in/del polymorphisms. We then constructed PRS using a Bayesian regression framework by placing a continuous shrinkage prior on SNP effect sizes using PRS-CS (34). PRS-CS uses LD information from an external reference panel (the 1000 Genomes European Phase 3 European sample here) (35), to estimate the posterior effect sizes for each SNP. Although $p$-value thresholding and clumping method (P-T) have been traditionally used for 
medRxiv preprint doi: https://doi.org/10.1101/2021.11.15.21266368; this version posted November 16, 2021. The copyright holder for this

PRS construction (36), PRS-CS has shown substantial improvement in predictive power over P-T (37). Similar to LDSC, PRS-CS limits the SNPs for PRS construction to around 1.2 million high-quality variants from the HapMap3 variants which provides 500 SNPs per LD block which substantially reduces memory and computational costs.

To show the specificity of the PRS constructed in our analysis, an additional PRS for low-density lipoprotein (LDL, N=87,048) from the ENGAGE Consortium (32) was also constructed using the same protocol described above. Genetic correlation estimates show that there is no significant correlation between LDL and psychiatric disorders, making LDL an appropriate phenotype as a negative control for this analysis $(38,39)$.

\section{Genomic Relationship Matrix, Principal Component and Statistical Analyses}

To account for the high degree of relatedness among individuals, analyses were carried out using a mixed-effects logistic regression model fitted by maximum likelihood by Nelder-Mead optimization using the GMMAT package (40) in R (41) The family structure was modelled as a random effect, with genomic relationship matrix (GRM) calculated using LDAK with LD correction parameters suited for families (42). In order to account for batch effects due to genotyping carried out on different arrays, we also included platform as a covariate. Principal component analysis (PCA) shows that all individuals in the sample are of European ancestry (Supplementary Figure 6-8). But to account for fine-scale structure within the Irish population (Supplementary Figure 9), the top 10 principal components (PC) were also included as covariates in the analysis. The final mixed regression model included GRM as a random effect covariate, with top 10 PCs, platform, and sex as fixed effect covariates. The final results were adjusted for multiple-comparison using the Holm method. In order to generate comparable odds ratios, all PRS underwent Z-score normalization. 
medRxiv preprint doi: https://doi.org/10.1101/2021.11.15.21266368; this version posted November 16, 2021. The copyright holder for this

\section{Results:}

\section{Multiplex SCZ families have an increased PRS for BIP and MDD.}

Table 1 presents the results from logistic mixed models per comparison group. As expected, LDL PRS used as the negative control in this study, shows no significant increase in members of multiplex SCZ families compared to population controls. Univariate BIP PRS was significantly higher in all diagnostic categories of multiplex SCZ families compared to population controls, except the unaffected individuals (only nominally significant). The highest odds ratio $(\mathrm{OR})$ was observed in the broad category (OR $=2.21$, $95 \% \mathrm{CI}=1.57-2.89$ ), which includes 17 of the $21 \mathrm{BIP}$ diagnosis in the ISHDSF. (Table 1). With the exception of the unaffected individuals in the families, MDD PRS was also significantly higher in all diagnostic categories compared to population controls, with the highest OR observed in the very broad category $(\mathrm{OR}=1.52,95 \% \mathrm{CI}=1.20-1.75)$, which includes 80 of $102 \mathrm{MDD}$ diagnosis in the ISHDSF, excluding MDD cases with psychotic features (Supplementary Table 1).

Table 1

\section{Increased BIP and MDD PRS in multiplex SCZ families are due to underlying $S C Z$ factors}

Next, we investigated whether the increased BIP and MDD polygenic risks in members of multiplex SCZ families are attributable to latent genetic factors that BIP or MDD share with SCZ, or to latent genetic factors that are unique to each disorder. (Supplementary Figure 4 for path diagram of the Cholesky decomposition). Using LDSC, we estimate the SNP-based heritability for SCZ factor underlying BIP $h_{S N P}^{2}$ $=0.3384(\mathrm{se}=0.0112)$, nonSCZ factor underlying BIP $h_{S N P}{ }^{2}=0.0448(\mathrm{se}=0.0023)$, and SCZ factor underlying MDD $h_{S N P}{ }^{2}=0.3397(\mathrm{se}=0.0116)$, nonSCZ factor underlying MDD $h_{S N P}{ }^{2}=0.0556(\mathrm{se}=$ 0.0022) (Supplementary Table 3). Manhattan and Q-Q plots for GWAS-by-subtraction models are represented in Figure 1 and 2, with full GWAS-by-subtraction results reported in in Supplementary Figures 6-11 and Supplementary Tables 3,4 and 13-18.

Figure 1 
medRxiv preprint doi: https://doi.org/10.1101/2021.11.15.21266368; this version posted November 16, 2021. The copyright holder for this

Figure 2

The PRS constructed for $S C Z$ factor underlying BIP and $S C Z$ factor underlying MDD were significantly higher in all diagnostic categories of multiplex SCZ families compared to population controls, with the highest OR observed in the narrow category $(S C Z$ factor in $\mathrm{BIP} \mathrm{OR}=6.11,95 \% \mathrm{CI}=$ 5.41-7.02; SCZ factor in MDD OR = 6.06, 95\% CI = 5.25-6.99) (Table 1, Figures 3,4). PRS constructed from nonSCZ factor in BIP and nonSCZ factor in MDD showed no significant increase in members of multiplex SCZ families compared to population controls (Table 1, Figures 3,4), indicating that the increased polygenic risk burden of BIP and MDD in multiplex SCZ families is likely to be fully attributable to the underlying latent genetic factor that BIP or MDD share in common with SCZ, as opposed to latent genetic factors or liabilities that are unique to BIP or MDD.

Figure 3

Figure 4

$\underline{\text { Replication. To demonstrate the generalizability of the results beyond multiplex families, we attempted }}$ a replication of the PRS comparison, in an independent sample of ancestry-matched singleton SCZ cases $(\mathrm{N}=2,224)$ from Ireland. The observed pattern of PRS enrichment in singleton SCZ cases is similar to the narrow category in multiplex SCZ families (which includes familial SCZ cases), showing the generalizability of these results in a cohort of non-related singleton SCZ cases from the sampe population. (Table 1).

\section{Discussion and Conclusions:}

Large-scale GWAS of SCZ, BIP, and MDD (18,19,30,31,43-45), have shown that many common risk variants with small effect sizes contribute to disease risk in psychiatric disorders, with cross-disorder 
medRxiv preprint doi: https://doi.org/10.1101/2021.11.15.21266368; this version posted November 16, 2021. The copyright holder for this preprint (which was not certified by peer review) is the author/funder, who has granted medRxiv a license to display the preprint in perpetuity. All rights reserved. No reuse allowed without permission.

analyses of psychiatric disorders also providing consistent evidence that SCZ, BIP, and MDD share substantial genetic risk at common variation level $(16,17,46)$. In light of these observations, we investigated the common genetic risk variation burden of BIP, MDD in multiplex SCZ families, and further disentangled the observed increased polygenic risks into underlying latent genetic factors. Our results indicate that members of multiplex SCZ families have an increased PRS for BIP and MDD, with GWAS-by-subtraction analyses showing that this increased polygenic risk is likely to be entirely attributable to genetic risk factors that BIP or MDD share with SCZ. In addition, LDL PRS used as a negative control, showed no significant difference between members of multiplex SCZ families and population controls, validiting the observed patterns of PRS enrichment for underlying genetic factors generated in this study. Furthermore, we replicated our findings in an independent, ancestry-matched sample of singleton SCZ cases, to show the generalizability of this observation in a cohort of singleton SCZ cases. Our results provide genetic evidence in support of previous epidemiological findings that shows an increased incidence of both psychotic and affective disorders in families with multiple SCZ cases $(5,6,13,47)$. Therefore, individuals in multiplex families may be genetically vulnerable to a range of psychotic and affective disorders, and in order to properly assess an individual's genetic risk for psychiatric disorders, familial backgrounds should be taken into consideration.

GenomicSEM framework results rely on latent factors that are inferred from the molecular data (20). Therefore, we attempted to further validate the GWAS-by-subtraction models by conducting comprehensive downstream follow-up analyses. We show that $S C Z$ and nonSCZ factor GWAS results generated from GWAS-by-subtraction models show strong polygenic signals with no evidence for confounding (Figures 1,2), and partitioning the heritability of these results into functional categories (48) reveals that both underlying factors for BIP or MDD are enriched in similar functional categories (Supplementary Tables 5-8). Furthermore, we show that GWAS-by-subtraction results are also significantly enriched in CNS tissues relevant to psychiatric disorders (Supplementary Figure 14 and Supplementary Table 17), and MAGMA tissue expression profile analysis (49) using GTEx v8 (50) also shows that genes from GWAS-by-subtraction analyses were significantly enriched for expression in 
medRxiv preprint doi: https://doi.org/10.1101/2021.11.15.21266368; this version posted November 16, 2021. The copyright holder for this preprint (which was not certified by peer review) is the author/funder, who has granted medRxiv a license to display the preprint in perpetuity. All rights reserved. No reuse allowed without permission.

nearly all central nervous system (CNS) tissues (Supplementary Figures 10-13 supplementary Table 15 ), with cell-type stratified LDSC (51) analyses also showing significant enrichment of genes found in neurons for GWAS-by-subtraction results, with no significant enrichment in oligodendrocytes and astrocytes (Supplementary Figure 14 and Supplementary Table 16), further underlining the validity of these results.

We note that increased polygenic risk for psychiatric disorders has been observed in other family and pedigree studies (52-54), however, the scope of the current study differs from previous studies. A distinct feature of the ISHDSF sample, is the presence of a broad range of psychiatric disorders, which allows for proper cross-disorder PRS analysis. In addition, to our knowledge, the ISHDSF sample also has the largest sample size $(\mathrm{N}=1,005)$ among currently published multiplex family PRS studies, and is the first to dissect polygenic risks into underlying genetic factors. Andlauer et al. (52) analyzed multiplex BIP families (N=395) consisting of 166 BIP and 78 MDD cases, and showed that familial BIP cases and their unaffected relatives, had a higher PRS for SCZ and BIP compared to population controls. Szatkiewicz et al. (53) used a densely affected pedigree from Northern Sweden $(\mathrm{N}=418)$ and showed an increased SCZ PRS in affected members compared to unaffected members and population controls. De Jong et al. (54) also used a dense pedigree $(\mathrm{N}=300)$ with BIP and MDD cases and showed nominally significant BIP and SCZ PRS in affected members compared to unaffected members and population controls. Our results, combined with previous cross-disorder analyses of multiplex families referenced above, suggest that we are only just beginning to tease apart the complex interactions underlying psychiatric disorders. Thus, as current GWAS sample sizes continue to increase, we will continue to reveal how these underlying genetic factors, both independently and through their covariance, contribute to complex psychiatric disorders and their genetic architectures at common variation level.

The analyses presented in this study should be interpreted in the context of some limitations.

The ISHDSF sample was ascertained to have 2 or more probands with SCZ or poor-outcome schizoaffective disorder. Therefore, some diagnostic categories in the families (e.g the broad category), have a lower number of individuals, which may potentially bias some of the results due to lower power. 
medRxiv preprint doi: https://doi.org/10.1101/2021.11.15.21266368; this version posted November 16, 2021. The copyright holder for this preprint (which was not certified by peer review) is the author/funder, who has granted medRxiv a license to display the preprint in perpetuity. All rights reserved. No reuse allowed without permission.

We addressed this by repeating the PRS analysis by grouping the individuals in a concentric manner as described in the original ISHDSF publication (6). The concentric comparison versus population controls showed similar patterns of PRS enrichment as observed in the separate comparisons presented in the main text, indicating that lower numbers of individuals in some of the diagnostic categories is unlikely to be a source of bias (Supplementary Table 19). Given that environmental factors have not been assessed here, future analyses could integrate environmental influences unique to the families to further elucidate the role of environmental factors on the elevated polygenic risk for BIP and MDD in multiplex SCZ families.

In conclusion, in this study we showed that members of multiplex SCZ families have an increased polygenic risk for BIP and MDD compared to ancestry-matched population controls. However, this observation is likely to be entirely attributable to latent genetic factors shared between SCZ and BIP, or $\mathrm{SCZ}$ and MDD, rather than latent genetic factors unique to BIP or MDD. These findings provide new insight for cross-disorder PRS analyses in psychiatric disorders, by cautioning that for complete interpretation of observed cross-disorder PRS enrichment, we must account for genetic correlations across correlated psychiatric disorders, as failure to do so, may result in erroneous conclusions about not only independent factors that contribute to polygenic architecture of complex psychiatric disorders, but also the degree to which complex psychiatric disorders are unique or related to each other. 


\section{Figures:}
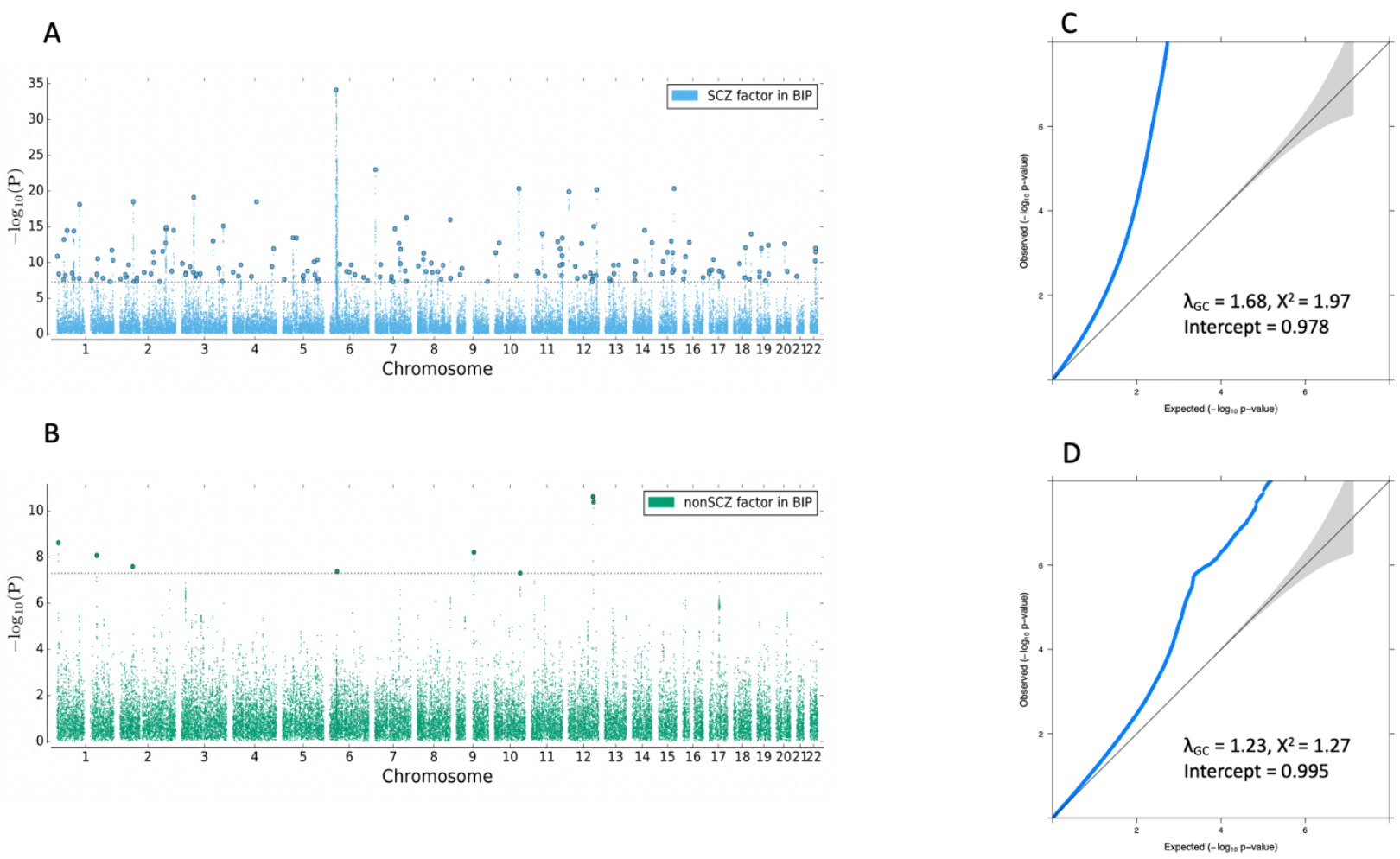

Figure 1. Manhattan and quantile-quantile plots for $S C Z$ factor and nonSCZ factor in BIP. A. Manhattan plot corresponding to the SNP effects for SCZ factor in BIP. B. Manhattan plot corresponding to the SNP effects for nonSCZ factor in BIP. The x-axis in A and $\mathbf{B}$ corresponds to the chromosome and the $y$-axis shows the $p$-value on the $-\log _{10}$ scale. The dotted line denotes genome-wide significance level of $5 \times 10^{-8}$. Lead SNPs are marked in bold. C. Quantile-quantile plot for $S C Z$ factor in BIP. D. Quantile-quantile plot for nonSCZ factor in BIP. The x-axis in C and $\mathbf{D}$ refers to expected $p$-value while the $\mathrm{y}$-axis refers to the observed $p$-value. 

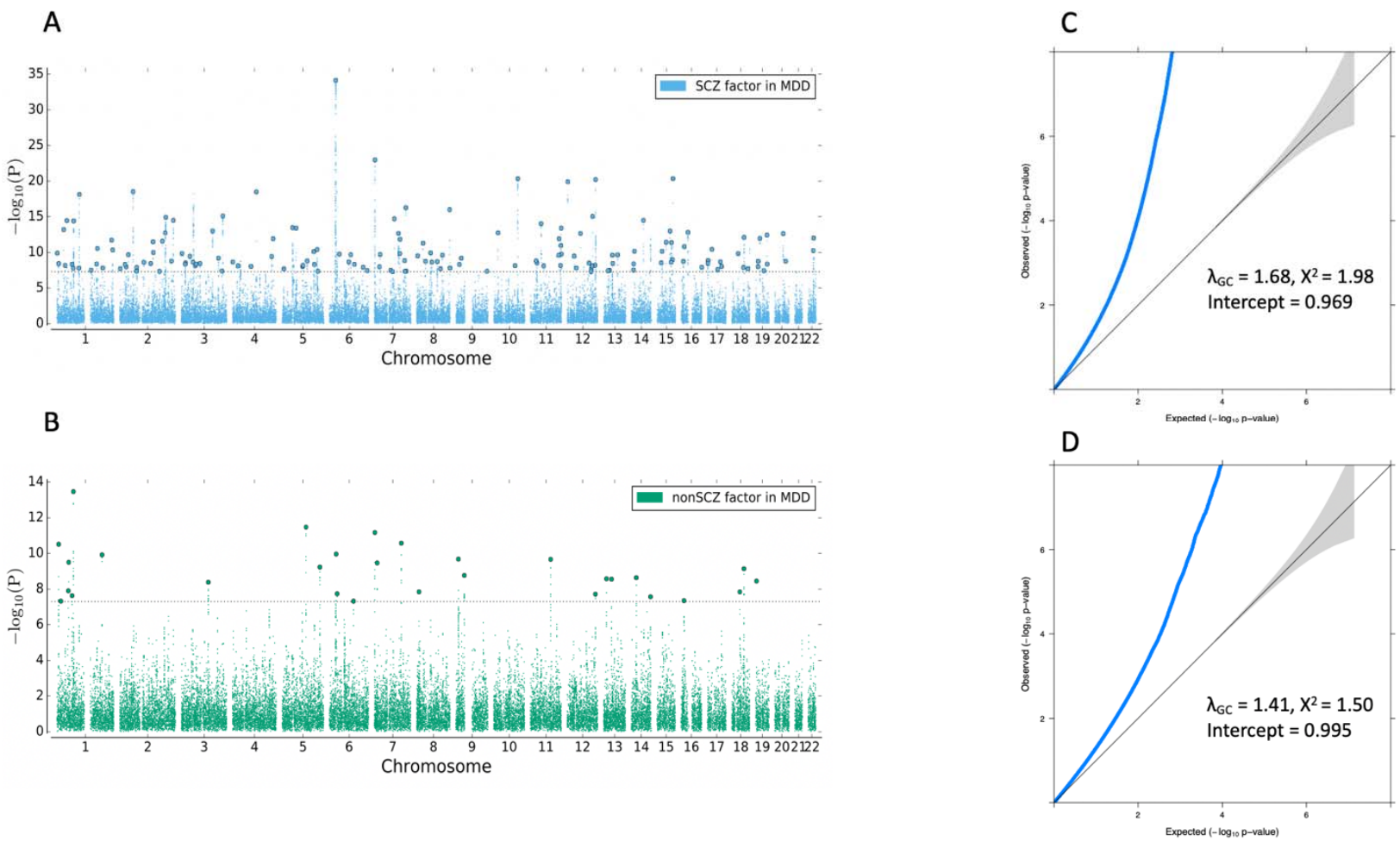

Figure 2. Manhattan and quantile-quantile plots for $S C Z$ factor and nonSCZ factor in MDD. A. Manhattan plot corresponding to the SNP effects for SCZ factor in MDD. B. Manhattan plot corresponding to the SNP effects for nonSCZ factor in MDD. The x-axis in $\mathbf{A}$ and $\mathbf{B}$ corresponds to the chromosome and the $y$-axis shows the $p$-value on the $-\log _{10}$ scale. The dotted line denotes genome-wide significance level of $5 \times 10^{-8}$. Lead SNPs are marked in bold. C. Quantile-quantile plot for $S C Z$ factor in MDD. D. Quantile-quantile plot for non $S C Z$ factor in MDD. The x-axis in $\mathbf{C}$ and $\mathbf{D}$ refers to expected $p$-value while the $\mathrm{y}$-axis refers to the observed $p$-value. 
A

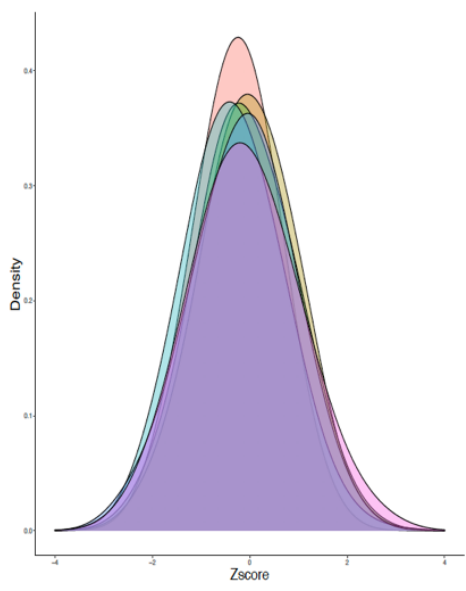

B

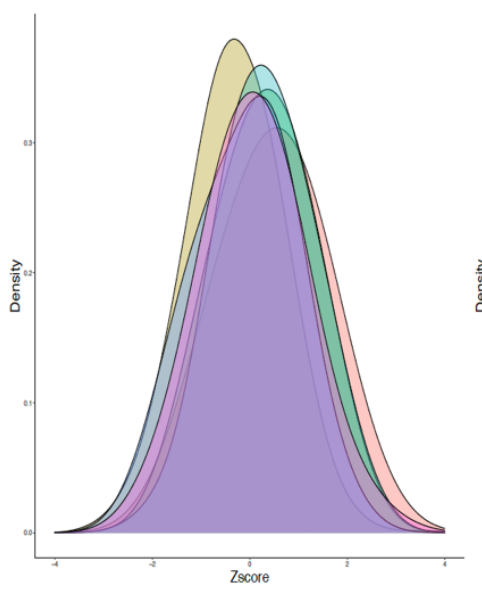

C

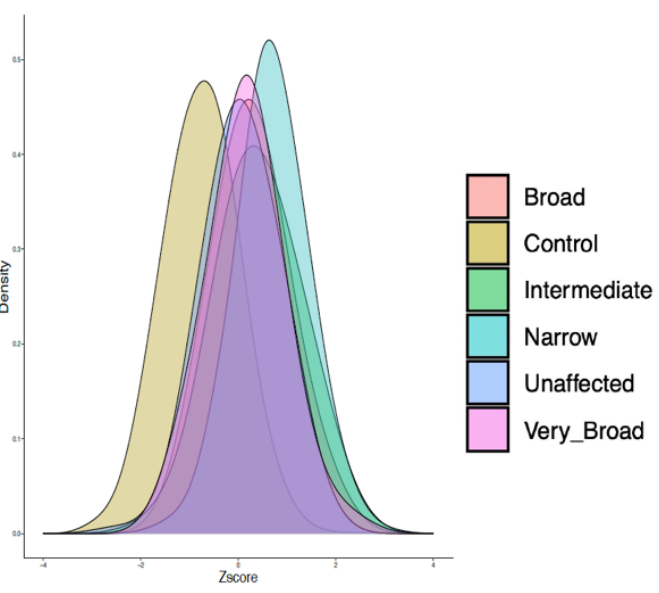

Figure 3. Density plots visualizing the distribution of BIP PRS in the ISHDSF sample. All PRS are Z-score standardized with mean of 0 and standard deviation of 1 . A. Distribution of nonSCZ factor in BIP PRS. B. Distribution of univariate BIP PRS. C. Distribution of SCZ factor in BIP PRS. No significant difference is observed for the nonSCZ factor PRS between different diagnostic categories in ISDHSF versus to population controls, whereas $S C Z$ factor PRS is significantly higher in all categories compared to population controls. Each color represents one of the diagnostic categories in ISHDSF sample on the psychosis spectrum (Supplementary Table 1 and Supplementary Figure 16)

A

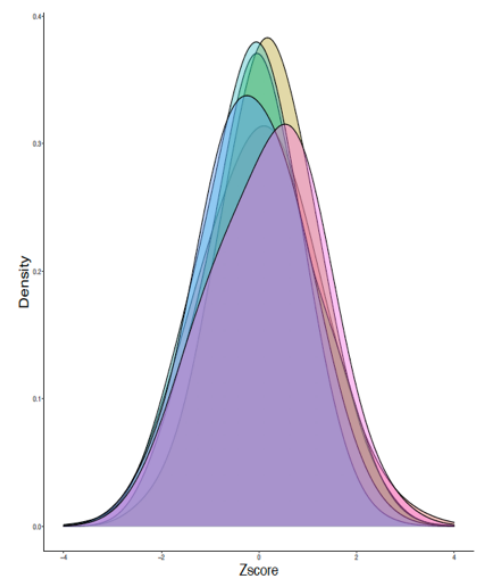

B

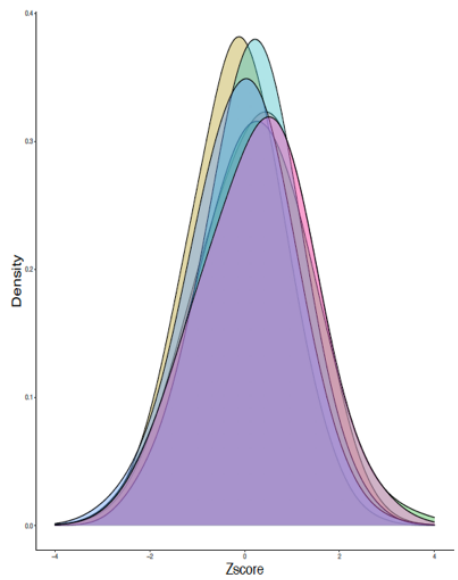

C

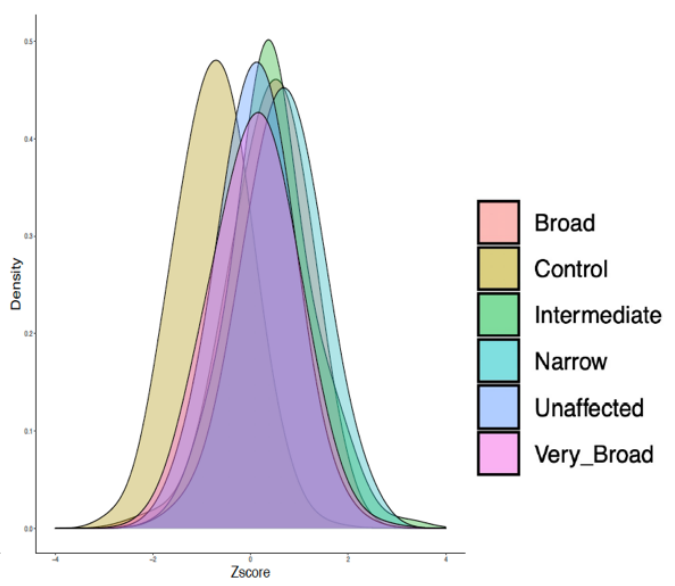

Figure 4. Density plots visualizing the distribution of MDD PRS in the ISHDSF sample. All PRS are Z-score standardized with mean of 0 and standard deviation of 1 . A. Distribution of nonSCZ factor in MDD PRS. B. Distribution of univariate MDD PRS. C. Distribution of $S C Z$ factor in MDD PRS. No significant difference is observed for the nonSCZ factor PRS between different diagnostic categories in ISDHSF versus to population controls, whereas $S C Z$ factor PRS is significantly higher in all categories compared to population controls. Each color represents one of the diagnostic categories in ISHDSF sample on the psychosis spectrum (Supplementary Table 1 and Supplementary Figure 16) 
medRxiv preprint doi: https://doi.org/10.1101/2021.11.15.21266368; this version posted November 16, 2021. The copyright holder for this preprint (which was not certified by peer review) is the author/funder, who has granted medRxiv a license to display the preprint in perpetuity. All rights reserved. No reuse allowed without permission.

\section{Table:}


medRxiv preprint doi: https://doi.org/10.1101/2021.11.15.21266368; this version posted November 16, 2021. The copyright holder for this preprint (which was not certified by peer review) is the author/funder, who has granted medRxiv a license to display the preprint in perpetuity. All rights reserved. No reuse allowed without permission.

\begin{tabular}{|c|c|c|c|c|}
\hline PRS & OR & $95 \% \mathrm{Cl}$ & P-Value & Holm-adjusted \\
\hline \multicolumn{5}{|c|}{ Narrow vs Population Controls } \\
\hline BIP & 1.93 & $1.69-2.20$ & $7.21 \mathrm{E}-23$ & $2.02 \mathrm{E}-21$ \\
\hline MDD & 1.35 & $1.98-1.53$ & $1.45 \mathrm{E}-06$ & $2.61 \mathrm{E}-05$ \\
\hline SCZ Factor in BIP & 6.11 & $5.41-7.02$ & $6.53 \mathrm{E}-69$ & $2.48 \mathrm{E}-87$ \\
\hline nonSCZ Factor in BIP & 0.97 & $0.51-1.24$ & 0.3 & 1 \\
\hline SCZ Factor in MDD & 6.06 & $5.25-6.99$ & $9.40 \mathrm{E}-60$ & $3.67 E-88$ \\
\hline nonSCZ Factor in MDD & 0.95 & $0.48-1.20$ & 0.37 & 1 \\
\hline LDL & 0.98 & $0.88-1.11$ & 0.82 & 1 \\
\hline \multicolumn{5}{|c|}{ Intermediate vs Population Controls } \\
\hline BIP & 1.84 & $1.48-2.29$ & $5.85 \mathrm{E}-08$ & $1.17 \mathrm{E}-06$ \\
\hline MDD & 1.43 & $1.17-1.75$ & $5.72 \mathrm{E}-04$ & $8.00 \mathrm{E}-03$ \\
\hline SCZ Factor in BIP & 5.76 & $4.72-7.22$ & $7.63 E-32$ & $2.48 \mathrm{E}-30$ \\
\hline nonSCZ Factor in BIP & 0.96 & $0.54-1.19$ & 0.16 & 1 \\
\hline SCZ Factor in MDD & 5.78 & $4.70-7.22$ & $7.50 \mathrm{E}-32$ & $2.48 \mathrm{E}-30$ \\
\hline nonSCZ Factor in MDD & 0.95 & $0.654-1.16$ & 0.11 & 1 \\
\hline LDL & 0.85 & $0.70-1.04$ & 0.13 & 1 \\
\hline \multicolumn{5}{|c|}{ Broad vs Population Controls } \\
\hline BIP & 2.21 & $1.57-2.89$ & $7.32 \mathrm{E}-07$ & $1.39 \mathrm{E}-05$ \\
\hline MDD & 1.41 & $1.05-1.90$ & $2.14 \mathrm{E}-02$ & $2.58 \mathrm{E}-01$ \\
\hline SCZ Factor in BIP & 4.39 & $2.95-5.64$ & $6.61 \mathrm{E}-15$ & $1.59 \mathrm{E}-13$ \\
\hline nonSCZ Factor in BIP & 0.99 & $0.517-1.26$ & 0.27 & 1 \\
\hline SCZ Factor in MDD & 4.22 & $2.87-5.83$ & $4.49 \mathrm{E}-15$ & $1.12 \mathrm{E}-13$ \\
\hline nonSCZ Factor in MDD & 0.98 & $0.63-1.11$ & 0.23 & 1 \\
\hline LDL & 0.88 & $0.62-1.08$ & 0.16 & 1 \\
\hline \multicolumn{5}{|c|}{ Very Broad vs Population Controls } \\
\hline BIP & 1.50 & $1.23-1.83$ & $5.60 \mathrm{E}-05$ & 8.96E-04 \\
\hline MDD & 1.52 & $1.20-1.75$ & $1.20 \mathrm{E}-04$ & $1.80 \mathrm{E}-03$ \\
\hline SCZ Factor in BIP & 3.89 & $2.90-5.01$ & $3.64 \mathrm{E}-26$ & $1.09 \mathrm{E}-24$ \\
\hline nonSCZ Factor in BIP & 0.97 & $0.60-1.20$ & 0.43 & 1 \\
\hline SCZ Factor in MDD & 3.85 & $2.88-4.92$ & $7.20 \mathrm{E}-25$ & $2.09 \mathrm{E}-23$ \\
\hline nonSCZ Factor in MDD & 0.94 & $0.66-1.18$ & 0.51 & 1 \\
\hline LDL & 1.01 & $0.84-1.22$ & 0.87 & 1 \\
\hline \multicolumn{5}{|c|}{ Unaffected vs Population Controls } \\
\hline BIP & 1.21 & $1.03-1.40$ & 0.003 & 0.06 \\
\hline MDD & 1.1 & $0.94-1.27$ & 0.23 & 1 \\
\hline SCZ Factor in BIP & 3.60 & $2.89-4.70$ & $1.36 \mathrm{E}-34$ & $4.76 \mathrm{E}-33$ \\
\hline nonSCZ Factor in BIP & 0.95 & $0.54-1.21$ & 0.33 & 1 \\
\hline SCZ Factor in MDD & 3.44 & $2.80-4.68$ & $1.16 \mathrm{E}-33$ & $3.94 \mathrm{E}-32$ \\
\hline nonSCZ Factor in MDD & 0.92 & $0.50-1.18$ & 0.55 & 1 \\
\hline LDL & 0.98 & $0.84-1.14$ & 0.85 & 1 \\
\hline \multicolumn{5}{|c|}{ Singleton Cases vs Population Controls } \\
\hline BIP & 1.75 & $1.63-1.88$ & $1.59 \mathrm{E}-52$ & $5.88 \mathrm{E}-51$ \\
\hline MDD & 1.35 & $1.26-1.44$ & $2.73 E-18$ & 7.37E-17 \\
\hline SCZ Factor in BIP & 5.35 & 4.55-6.19 & $1.30 \mathrm{E}-22$ & $5.33 E-20$ \\
\hline nonSCZ Factor in BIP & 0.98 & $0.60-1.25$ & 0.22 & 1 \\
\hline SCZ Factor in MDD & 5.11 & $4.40-5.91$ & $4.08 \mathrm{E}-22$ & $1.71 \mathrm{E}-20$ \\
\hline nonSCZ Factor in MDD & 0.97 & $0.54-1.21$ & 0.18 & 1 \\
\hline LDL & 0.99 & $0.93-1.06$ & 0.92 & 1 \\
\hline
\end{tabular}


Table 1: Comparison of the PRS in all diagnostic categories of ISHDSF from mixed-effects logistic regression models. All the $p$-values are one-sided and results are following the hypothesis that diagnostic categories in the families have higher PRS than population controls. $P$-value column represents the significance level before multiple testing corrections. Holm-adjusted $P$-value column represents the $p$ values adjusted for multiple testing correction using the Holm method OR and 95\% CI are provided for effect sizes. Singleton cases versus population controls comparison follows the hypothesis that singleton cases have higher PRS than population controls.

\section{Code Availability:}

All the scripts used in this study will be made publicly available upon publication.

We made use of various freely available software tools in this study:

Plink2: https://www.cog-genomics.org/plink/2.0/

GenomicSEM: https://github.com/GenomicSEM/GenomicSEM

PRS-CS: https://github.com/getian107/PRScs

MiXeR: https://github.com/precimed/mixer

LDSC: https://github.com/bulik/ldsc

GMMAT: https://github.com/hanchenphd/GMMAT

LDAK: http://dougspeed.com/ldak/

\section{Data Availability:}

GWAS summary statistics for SCZ, BIP, MDD, and LDL are publicly available.

PGC3-SCZ: https://www.med.unc.edu/pgc/download-results/

PGC3-BIP: https://www.med.unc.edu/pgc/download-results/

PGC2-MDD-UKB Meta-analysis: https://datashare.ed.ac.uk/handle/10283/3203

LDL: http://diagram-consortium.org/2015_ENGAGE_1KG/

GWAS-by-subtraction summary statistics generated in this study will be made publicly available upon publication.

\section{Funding and Acknowledgements:}

MA, BCV, S-AB, KSK, BTW and BR were supported by R01-MH114593 (to Dr. Riley). Production of

GWAS data for singleton cases and controls was supported by R01-MH083094 (to Dr. Riley) and

Wellcome Trust Case Control Consortium 2 project (085475/B/08/Z and 085475/Z/08/Z), and the

Wellcome Trust (072894/Z/03/Z, 090532/Z/09/Z and 075491/Z/04/B), and NIMH grant MH 41953 and 
medRxiv preprint doi: https://doi.org/10.1101/2021.11.15.21266368; this version posted November 16, 2021. The copyright holder for this

Science Foundation Ireland (08/IN.1/B1916). Production of GWAS data for multiplex families was supported by R01-MH062276 and R01-MH068881 (to Dr. Riley). T-HN was supported by NARSAD Young Investigator Grant 28599.

This study was approved by Virginia Commonwealth University Office of Research Subject Protection, and all necessary patient/participant consent has been obtained and the appropriate institutional forms have been archived.

Membership of the Irish Schizophrenia Genomics Consortium (ISGC):

Brien P Riley ${ }^{1}$, Derek W Morris ${ }^{2}$, Colm T O’Dushlaine ${ }^{3}$, Paul Cormican ${ }^{4}$, Elaine M Kenny ${ }^{3}$, Brandon Wormley $^{1}$, Gary Donohoe ${ }^{2}$, Emma Quinn $^{3}$, Roisin Judge ${ }^{3}$, Kim Coleman $^{3}$, Daniela Tropea ${ }^{3}$, Siobhan Roche $^{5}$, Liz Cummings ${ }^{3}$, Eric Kelleher ${ }^{3}$, Patrick McKeon ${ }^{5}$, Ted Dinan $^{6}$, Colm McDonald $^{2}$, Kieran C Murphy $^{7}$, Eadbhard O'Callaghan ${ }^{8}$, Francis A O’Neill ${ }^{9}$, John L Waddington ${ }^{10}$, Ken S Kendler ${ }^{1}$, Michael Gill $^{3}$, Aiden Corvin ${ }^{3}$

1 Depts of Psychiatry and Human Genetics, Virginia Institute of Psychiatric and Behavioral Genetics, Virginia Commonwealth University, Richmond, VA, USA;

2 Centre for Neuroimaging and Cognitive Genomics (NICOG), School of Psychology, National University of Ireland Galway, Ireland; School of Natural Sciences, National University of Ireland Galway, Ireland;

${ }^{3}$ Neuropsychiatric Genetics Research Group, Institute of Molecular Medicine, Trinity College Dublin, Dublin, Ireland;

${ }^{4}$ Animal and Grassland Research and Innovation Centre, Teagasc, Grange, Dunsany, County Meath, Ireland;

${ }^{5}$ St Patrick's University Hospital, James St., Dublin, Ireland;

${ }^{6}$ Department of Psychiatry, University College Cork, Cork, Ireland; 
medRxiv preprint doi: https://doi.org/10.1101/2021.11.15.21266368; this version posted November 16, 2021. The copyright holder for this

${ }^{7}$ Department of Psychiatry, Royal College of Surgeons in Ireland, Dublin, Ireland;

${ }^{8}$ DETECT Early Psychosis Service, Blackrock, Co. Dublin, Ireland;

${ }^{9}$ Centre for Public Health, Institute of Clinical Sciences, Queen's University Belfast, Belfast, UK;

${ }^{10}$ Molecular and Cellular Therapeutics, Royal College of Surgeons in Ireland, Dublin, Ireland;

\section{Conflict of Interest:}

None reported.

\section{References:}

1. Kendler KS. Diagnostic approaches to schizotypal personality disorder: a historical perspective. Schizophr Bull. 1985;11(4):538-53.

2. Zerbin-Rüdin E, Kendler KS. Ernst Rüdin (1874-1952) and his genealogic-demographic department in Munich (1917-1986): an introduction to their family studies of schizophrenia. Am J Med Genet. 1996;67(4):332-7.

3. Kety SS, Rosenthal D, Wender PH, Schulsinger F, Jacobsen B. Mental illness in the biological and adoptive families of adopted individuals who have become schizophrenic: a preliminary report based on psychiatric interviews. Proc Annu Meet Am Psychopathol Assoc. 1975;(63):147-65.

4. Kety SS, Wender PH, Jacobsen B, Ingraham LJ, Janson L, Faber B, et al. Mental Illness in the Biological and Adoptive Relatives of Schizophrenic Adoptees: Replication of the Copenhagen Study in the Rest of Denmark. Arch Gen Psychiatry. 1994;51(6):442-55.

5. Kendler KS, Neale MC, Walsh D. Evaluating the spectrum concept of schizophrenia in the Roscommon Family Study. Am J Psychiatry. 1995;152(5):749-54.

6. Kendler KS, O’Neill FA, Burke J, Murphy B, Duke F, Straub RE, et al. Irish study of 
medRxiv preprint doi: https://doi.org/10.1101/2021.11.15.21266368; this version posted November 16, 2021. The copyright holder for this

high-density schizophrenia families: Field methods and power to detect linkage. Am $\mathbf{J}$

Med Genet - Semin Med Genet. 1996;67(2):179-90.

7. Asarnow RF, Nuechterlein KH, Fogelson D, Subotnik KL, Payne DA, Russell AT, et al.

Schizophrenia and schizophrenia-spectrum personality disorders in the first-degree relatives of children with schizophrenia: The UCLA Family Study. Arch Gen Psychiatry. 2001;58(6):581-8.

8. Baron M, Gruen R, Asnis L, Kane J. Familial relatedness of schizophrenia and schizotypal states. Am J Psychiatry. 1983;140(11):1437-42.

9. Kendler KS, McGuire M, Gruenberg AM, O’Hare A, Spellman M, Walsh D. The

Roscommon Family Study: I. Methods, Diagnosis of Probands, and Risk of Schizophrenia in Relatives. Arch Gen Psychiatry. 1993;50(7):527-40.

10. Kendler KS, McGuire M, Gruenberg AM, Spellman M, O'Hare A, Walsh D. The Roscommon Family Study: II. The Risk of Nonschizophrenic Nonaffective Psychoses in Relatives. Arch Gen Psychiatry. 1993;50(8):645-52.

11. Kendler KS, McGuire M, Gruenberg AM, O’Hare A, Spellman M, Walsh D. The Roscommon Family Study: III. Schizophrenia-Related Personality Disorders in Relatives. Arch Gen Psychiatry. 1993;50(10):781-8.

12. Kendler KS, McGuire M, Gruenberg AM, O’Hare A, Spellman M, Walsh D. The Roscommon Family Study: IV. Affective Illness, Anxiety Disorders, and Alcoholism in Relatives. Arch Gen Psychiatry. 1993;50(12):952-60.

13. Ahangari M, Gentry AE, Nguyen T-H, Verrelli B, Bacanu S-A, Kirkpatrick R, et al. Evaluating the role of common risk variation in the recurrence risk of schizophrenia in multiplex schizophrenia families. medRxiv. 2021 Jan 1;2021.06.21.21259285. 
medRxiv preprint doi: https://doi.org/10.1101/2021.11.15.21266368; this version posted November 16, 2021. The copyright holder for this

14. Lee PH, Anttila V, Won H, Feng YCA, Rosenthal J, Zhu Z, et al. Genomic Relationships, Novel Loci, and Pleiotropic Mechanisms across Eight Psychiatric Disorders. Cell. 2019;179(7):1469-1482.e11.

15. Smoller JW, Kendler K, Craddock N, Lee PH, Neale BM, Nurnberger JN, et al. Identification of risk loci with shared effects on five major psychiatric disorders: A genome-wide analysis. Lancet. 2013;381(9875):1371-9.

16. Docherty AR, Moscati AA, Fanous AH. Cross-Disorder Psychiatric Genomics. Curr Behav Neurosci Reports. 2016;3(3):256-63.

17. Lee PH, Feng YCA, Smoller JW. Pleiotropy and Cross-Disorder Genetics Among Psychiatric Disorders. Biol Psychiatry. 2021;89(1):20-31.

18. Mullins N, Forstner AJ, O’Connell KS, Coombes B, Coleman JRI, Qiao Z, et al. Genomewide association study of more than 40,000 bipolar disorder cases provides new insights into the underlying biology. Nat Genet. 2021;53(6):817-29.

19. Wray NR, Ripke S, Mattheisen M, Trzaskowski M, Byrne EM, Abdellaoui A, et al. Genome-wide association analyses identify 44 risk variants and refine the genetic architecture of major depression. Nat Genet. 2018;50(5):668-81.

20. Grotzinger AD, Rhemtulla M, de Vlaming R, Ritchie SJ, Mallard TT, Hill WD, et al. Genomic structural equation modelling provides insights into the multivariate genetic architecture of complex traits. Nat Hum Behav. 2019;3(5):513-25.

21. Demange PA, Malanchini M, Mallard TT, Biroli P, Cox SR, Grotzinger AD, et al. Investigating the genetic architecture of noncognitive skills using GWAS-by-subtraction. Nat Genet. 2021;53(1):35-44.

22. Levinson DF, Shi J, Wang K, Oh S, Riley B, Pulver AE, et al. Genome-wide association 
medRxiv preprint doi: https://doi.org/10.1101/2021.11.15.21266368; this version posted November 16, 2021. The copyright holder for this

study of multiplex schizophrenia pedigrees. Am J Psychiatry. 2012;169(9):963-73.

23. Donnelly P, Barroso I, Blackwell JM, Bramon E, Brown MA, Casas JP, et al. Genomewide association study implicates HLA-C*01:02 as a risk factor at the major histocompatibility complex locus in schizophrenia. Biol Psychiatry. 2012;72(8):620-8.

24. Colhoun HM, McKeigue PM, Smith GD. Problems of reporting genetic associations with complex outcomes. Vol. 361, Lancet. 2003. p. 865-72.

25. Riley B, Thiselton D, Maher BS, Bigdeli T, Wormley B, McMichael GO, et al. Replication of association between schizophrenia and ZNF804A in the Irish Case-Control Study of Schizophrenia sample. Mol Psychiatry. 2010;15(1):29-37.

26. Loh PR, Danecek P, Palamara PF, Fuchsberger C, Reshef YA, Finucane HK, et al. Reference-based phasing using the Haplotype Reference Consortium panel. Nat Genet. 2016;48(11):1443-8.

27. McCarthy S, Das S, Kretzschmar W, Delaneau O, Wood AR, Teumer A, et al. A reference panel of 64,976 haplotypes for genotype imputation. Nat Genet. 2016;48(10):1279-83.

28. Das S, Forer L, Schönherr S, Sidore C, Locke AE, Kwong A, et al. Next-generation genotype imputation service and methods. Nat Genet. 2016;48(10):1284-7.

29. Auton A, Abecasis GR, Altshuler DM, Durbin RM, Bentley DR, Chakravarti A, et al. A global reference for human genetic variation. Vol. 526, Nature. 2015. p. 68-74.

30. Consortium SWG of the PG, Ripke S, Walters JT, O’Donovan MC. Mapping genomic loci prioritises genes and implicates synaptic biology in schizophrenia. medRxiv. 2020;2020.09.12.20192922.

31. Howard DM, Adams MJ, Clarke TK, Hafferty JD, Gibson J, Shirali M, et al. Genomewide meta-analysis of depression identifies 102 independent variants and highlights the 
medRxiv preprint doi: https://doi.org/10.1101/2021.11.15.21266368; this version posted November 16, 2021. The copyright holder for this

importance of the prefrontal brain regions. Nat Neurosci. 2019;22(3):343-52.

32. Surakka I, Horikoshi M, Mägi R, Sarin AP, Mahajan A, Lagou V, et al. The impact of low-frequency and rare variants on lipid levels. Nat Genet. 2015;47(6):589-97.

33. Bulik-Sullivan B, Loh P-R, Finucane H, Ripke S, Yang J, Patterson N, et al. LD Score Regression Distinguishes Confounding from Polygenicity in Genome-Wide Association Studies. bioRxiv. 2014;002931.

34. Ge T, Chen CY, Ni Y, Feng YCA, Smoller JW. Polygenic prediction via Bayesian regression and continuous shrinkage priors. Nat Commun. 2019;10(1).

35. Clarke L, Fairley S, Zheng-Bradley X, Streeter I, Perry E, Lowy E, et al. The international Genome sample resource (IGSR): A worldwide collection of genome variation incorporating the 1000 Genomes Project data. Nucleic Acids Res. 2017;45(D1):D854-9.

36. Purcell SM, Wray NR, Stone JL, Visscher PM, O’Donovan MC, Sullivan PF, et al. Common polygenic variation contributes to risk of schizophrenia and bipolar disorder. Nature. 2009;460(7256):748-52.

37. Ni G, Zeng J, Revez JA, Wang Y, Zheng Z, Ge T, et al. A comparison of ten polygenic score methods for psychiatric disorders applied across multiple cohorts. Biol Psychiatry. 2021;

38. Zheng J, Erzurumluoglu AM, Elsworth BL, Kemp JP, Howe L, Haycock PC, et al. LD Hub: A centralized database and web interface to perform LD score regression that maximizes the potential of summary level GWAS data for SNP heritability and genetic correlation analysis. Bioinformatics. 2017;33(2):272-9.

39. Bulik-Sullivan B, Finucane HK, Anttila V, Gusev A, Day FR, Loh PR, et al. An atlas of genetic correlations across human diseases and traits. Nat Genet. 2015;47(11):1236-41. 
medRxiv preprint doi: https://doi.org/10.1101/2021.11.15.21266368; this version posted November 16, 2021. The copyright holder for this

40. Chen H, Wang C, Conomos MP, Stilp AM, Li Z, Sofer T, et al. Control for Population Structure and Relatedness for Binary Traits in Genetic Association Studies via Logistic Mixed Models. Am J Hum Genet. 2016;98(4):653-66.

41. R Core Team. R: A Language and Environment for Statistical Computing. 2020;

42. Speed D, Hemani G, Johnson MR, Balding DJ. Improved heritability estimation from genome-wide SNPs. Am J Hum Genet. 2012;91(6):1011-21.

43. Stahl EA, Breen G, Forstner AJ, McQuillin A, Ripke S, Trubetskoy V, et al. Genomewide association study identifies 30 loci associated with bipolar disorder. Nat Genet. 2019;51(5):793-803.

44. Visscher PM, Wray NR, Zhang Q, Sklar P, McCarthy MI, Brown MA, et al. 10 Years of GWAS Discovery: Biology, Function, and Translation. Vol. 101, American Journal of Human Genetics. 2017. p. 5-22.

45. Ripke S, Neale BM, Corvin A, Walters JTR, Farh KH, Holmans PA, et al. Biological insights from 108 schizophrenia-associated genetic loci. Nature. 2014;

46. Lee SH, Ripke S, Neale BM, Faraone S V., Purcell SM, Perlis RH, et al. Genetic relationship between five psychiatric disorders estimated from genome-wide SNPs. Nat Genet. 2013;45(9):984-94.

47. Bigdeli TB, Bacanu SA, Webb BT, Walsh D, O’Neill FA, Fanous AH, et al. Molecular validation of the schizophrenia spectrum. Schizophr Bull. 2014;40(1):60-5.

48. Finucane HK, Bulik-Sullivan B, Gusev A, Trynka G, Reshef Y, Loh PR, et al. Partitioning heritability by functional annotation using genome-wide association summary statistics. Nat Genet. 2015;47(11):1228-35.

49. de Leeuw CA, Mooij JM, Heskes T, Posthuma D. MAGMA: Generalized Gene-Set 
medRxiv preprint doi: https://doi.org/10.1101/2021.11.15.21266368; this version posted November 16, 2021. The copyright holder for this

Analysis of GWAS Data. PLoS Comput Biol. 2015;11(4).

50. Aguet F, Barbeira AN, Bonazzola R, Brown A, Castel SE, Jo B, et al. The GTEx Consortium atlas of genetic regulatory effects across human tissues. Science (80- ). 2020;369(6509):1318-30.

51. Finucane H, Reshef Y, Anttila V, Slowikowski K, Gusev A, Byrnes A, et al. Heritability enrichment of specifically expressed genes identifies disease-relevant tissues and cell types. Heritability Enrich specifically expressed genes identifies Dis tissues cell types. $2017 ; 103069$.

52. Andlauer TFM, Guzman-Parra J, Streit F, Strohmaier J, González MJ, Gil Flores S, et al. Bipolar multiplex families have an increased burden of common risk variants for psychiatric disorders. Mol Psychiatry. 2019;

53. Szatkiewicz J, Crowley JJ, Adolfsson AN, Åberg KA, Alaerts M, Genovese G, et al. The genomics of major psychiatric disorders in a large pedigree from Northern Sweden. Transl Psychiatry. 2019;9(1).

54. de Jong S, Diniz MJA, Saloma A, Gadelha A, Santoro ML, Ota VK, et al. Applying polygenic risk scoring for psychiatric disorders to a large family with bipolar disorder and major depressive disorder. Commun Biol. 2018;1(1). 